\title{
Avaliação da inserção da odontologia no Programa Saúde da Família de Pompéu (MG): a satisfação do usuário
}

\author{
The evaluation of the dental service inclusion \\ in the Family Health Program of Pompéu (MG): \\ the user satisfaction
}

Karina Lane Campos Andrade 1

Efigênia Ferreira e Ferreira 1

\begin{abstract}
In order to study the dental service inclusion in the Family Health Program of Pompéu city, Minas Gerais, a group of 120 users were interviewed in Volta do Brejo district. A questionnary was used. The main problems reported were prompt service and resolute dental care. The Health Communitaries Agents and the short distance between the headquarter and the user's residences were positive factors. The "mouth problems" remained without solution as those observed in the health: inequalities in access, no integrated, insufficient workers and financial resources.

Keywords Program, Family Health Program, Dental care
\end{abstract}

Resumo Para avaliar a inserção da odontologia no Programa Saúde da Família (PSF) do município de Pompéu, Minas Gerais, pelo olhar do usuário, foi entrevistado um grupo de 120 usuários do PSF do bairro Volta do Brejo (estimativa de proporção, grau de confiança de 90\%). Como instrumento de coleta de dados, foi utilizado um questionário. As principais queixas dos usuários foram relacionadas à presteza no atendimento e à resolutividade do serviço. Como fatores positivos, elucidaram a presença dos agentes comunitários de saúde (ACS) e a proximidade da unidade de saúde das suas residências. Os "problemas de boca" ficam, assim, sem solução como os observados na saúde: desigualdades no acesso, ausência de integralidade, insuficiência de pessoal, insuficiência de recursos financeiros.

Palavras-chave Avaliação, Programa Saúde da Família, Odontologia, Usuário

\footnotetext{
1 Faculdade de Odontologia,

Universidade Federal

de Minas Gerais.

Rua Guajajaras 712/602,

Centro, 30180-100,

Belo Horizonte MG

karinalane@hotmail.com

e karilane@gmail.com
} 


\section{Introdução}

O Programa Saúde da Família (PSF) foi criado pelo Ministério da Saúde em 1994 e o documento que define as bases do programa destaca que ao contrário do modelo tradicional, centrado na doença e no hospital, o PSF prioriza as ações de proteção e promoção à saúde dos indivíduos e da família, tanto adultos, quanto crianças, sadios ou doentes, de forma integral e contínua (Trad \& Bastos 1 ).

O PSF, no discurso oficial, é uma estratégia para consolidação do Sistema Único de Saúde seguindo os seus princípios de universalidade, descentralização, integralidade e participação da comunidade. Garantir a atenção integral aos indivíduos é um dos seus principais objetivos, sendo que, apesar de estar no primeiro nível de atenção denominado atenção básica, a Unidade de Saúde da Família deve estar ligada a uma rede de serviços de forma a garantir a referência e contra-referência para a resolução de problemas (Brasil2).

Desde a sua criação, o número de municípios que implantaram o Programa Saúde da Família cresceu exponencialmente. Neste contexto, estudar o Programa Saúde da Família justifica-se como prática fortemente vigente que vem sofrendo modificações ao longo de sua consolidação, muitas vezes surgindo como uma nova opção para sistemas locais sem recursos, em função de incentivos financeiros oferecidos pelo governo. A inclusão da odontologia mais recentemente é uma das grandes modificações no Programa.

A publicação da Portaria Ministerial no 1.444 , de 28 de dezembro de 2000, anunciou oficialmente a inserção de "profissionais de saúde bucal” no PSF. A inserção da odontologia poderia, ocorrer sob duas modalidades, com variações dos incentivos financeiros: a modalidade I, composta de um cirurgião-dentista (CD) e um atendente de consultório dentário (ACD) e a modalidade 2, de um CD, um ACD e um técnico em higiene dentária (THD) (Brasil2).

As distorções, inadequações ou os inegáveis avanços alcançados em algumas localidades têm sido objeto de estudos em fóruns e trabalhos científicos.

Considerando estudos como o de Santos ${ }^{3}$ que enfatizou que a satisfação do usuário é um instrumento avaliador realmente verdadeiro e que deve ser o objetivo final de todo serviço de saúde, optou-se por avaliar este aspecto.

Vasconcelos 4 observa que em alguns municípios que já implantaram o PSF não está ocor- rendo ainda uma discussão aprofundada do modo de relação entre os profissionais e a população local. Para o autor, em alguns municípios, o Programa significou mais uma modificação institucional (nova divisão de trabalho entre os profissionais, deslocamento do local de atuação, acréscimo na remuneração da equipe, entre outros) do que uma maior aproximação com o cotidiano das famílias. Passam a ser denominadas "saúde da família" práticas tradicionais de abordagem individual ou de relação com os grupos comunitários. Muitas vezes, não se identificam as várias situações de risco vivenciadas pelas famílias ou entre os diversos contextos familiares em que se situam os problemas de saúde e, portanto, não existe a preocupação na utilização das diferentes metodologias de abordagem necessárias. Isso ocorre porque o eixo que orienta a intervenção familiar são os programas de saúde pública definidos e padronizados nas instâncias hierarquicamente superiores da burocracia do setor saúde. A percepção e a intervenção dos profissionais locais tendem, então, a ficar restritas. Nas visitas às famílias, a atenção fica muito dirigida aos aspectos que os diversos programas priorizam, como a amamentação, o uso de reidratante oral, o controle de hipertensão e outros. Se de um lado esta padronização facilita a expansão do programa, de outro lado simplifica e empobrece seu alcance por não se considerar a complexidade das manifestações locais dos problemas de saúde.

Para Trad e Bastos ${ }^{1}$, o controle social fortalecido com o advento do SUS e o incentivo à participação da comunidade pressupõem uma concepção do usuário do sistema com competência para avaliar e intervir modificando o próprio sistema. Estes autores situam o aumento do interesse pela avaliação da satisfação do usuário em inícios dos anos 70 e elucida que abordar a satisfação dos usuários implica trazer um julgamento sobre características dos serviços e, portanto, sobre sua qualidade. Assim, a perspectiva do usuário fornece informação essencial para completar e equilibrar a qualidade dos serviços.

Guedes \& Garcia ${ }^{5}$ estudaram a satisfação do usuário do serviço e verificaram que as respostas dos usuários acerca de seu nível de satisfação quanto ao atendimento nos serviços do SUS apresentam um direcionamento para as respostas positivas (ficando em torno de $40 \%$ a $50 \%$ ), pois há um receio de que as respostas desfavoráveis possam resultar em algum tipo de sanção no atendimento. Por outro lado, quan- 
do o entrevistador não é uma pessoa da comunidade, a tendência pode ser a resposta negativa.

Ferreira Filho et al. (1996)6, em seu estudo sobre avaliação de qualidade de serviço, dizem que quando a pesquisa realizada com os usuários é feita fora do espaço assistencial, além das críticas aos serviços serem feitas mais facilmente, observa-se que a insatisfação maior é gerada quando a atenção curativa ou de caráter emergencial não é bem resolvida. Estes autores consideram ainda que as condições de moradia das pessoas entrevistadas devem ser levadas em consideração ao se fazer uma pesquisa abordando o nível de satisfação do usuário, pois muitas vezes o que parece precário para alguns pode parecer excelente para alguém que tem de dividir seu metro quadrado com mais quatorze pessoas e para chegar em casa, além de subir o morro, tem de atravessar pelo menos quatro valões de esgoto.

No seu estudo de avaliação da qualidade de serviços de saúde, Santos ${ }^{3}$ observou que, entre as reclamações dos usuários, aparece com freqüência o "não ter conseguido tudo o que precisavam". Entre os itens citados, destacam-se a falta da atenção curativa e a dificuldade em conseguir medicamentos. Assim, as principais sugestões dadas pelos usuários recaíram sobre o aumento de profissionais no quadro e o cumprimento dos horários por parte dos funcionários, principalmente dos médicos.

Regis Filho \& Lopes $^{7}$ desenvolveram um estudo sobre perfil dos usuários e nível de satisfação em um serviço ambulatorial. Questionados sobre sua satisfação quanto aos horários de visitas dos agentes comunitários, cerca de 90\% das pessoas se disseram muito satisfeitas.

O município de Pompéu está localizado no centro-oeste mineiro, na região do Alto São Francisco. A população do município é de 24.937 habitantes, a grande maioria está concentrada na zona urbana, o que corresponde a 21.445, restando 3.492 habitantes na zona rural. A economia do município está voltada basicamente para a agropecuária. A maioria da população tem renda de até um salário mínimo (55,1\%), 30,7\% têm renda de 1 a 3 salários mínimos; $5,0 \%$, de 3 a 5 salários mínimos; e 9,1\%, mais de 5 salários mínimos. Da população total do município cerca de $74.5 \%$ são alfabetizados. O município se habilitou à condição de Gestão Plena da Atenção Básica, de acordo com a Norma Operacional Básica/96 (NOB/96).

Pompéu tem uma proporção de um cirurgião-dentista para 1.700 habitantes $(1 / 1.700$
CD/hab.). Andrade 8 mostrou em seu trabalho que o índice para ataque de cárie (CPO-d) médio aos 12 anos foi de 6.45 (OMS preconizou para o ano 2000 um valor aceitável de CPO-d= 3.0 para os 12 anos) (Brasil2).

A água de abastecimento público é fluoretada com ácido fluossilícico $(0.7$ ppmF) e dos 6.900 domicílios permanentes, 5.800 têm acesso à água tratada.

O município iniciou a mudança do modelo assistencial, basicamente centrado na doença e no modelo hospitalocêntrico, implantando o Programa de Saúde da Família em novembro de 1997. Iniciou-se o trabalho com uma equipe atuando em uma região escolhida segundo nível de carências/demanda, observando os levantamentos epidemiológicos realizados e também pela concentração populacional. Até o ano de 2002 formaram-se mais quatro equipes, $\mathrm{cu}$ ja abrangência é de quase $100 \%$ da população.

Em março de 2001 o município incluiu a odontologia na equipe de PSF e, considerando a relação de duas equipes de saúde para uma de odontologia, incluiu a região da Volta do Brejo e Várzea das Flores, iniciando com uma equipe na modalidade I da classificação proposta pelo Ministério da Saúde (um cirurgião-dentista e um atendente de consultório dentário).

As falhas estruturais foram detectadas no início da implantação do programa. O profissional foi contratado e não havia um espaço físico para realização do atendimento da população, assim sendo, realizava as visitas domiciliares somente.

Após algumas semanas, a cirurgiã-dentista iniciou o atendimento clínico na Escola Municipal José Maria de Carvalho. Nesse local havia um consultório montado destinado a atender os alunos da Escola no horário da manhã por uma profissional do Estado. A cirurgiã-dentista do PSF atendia à tarde, alternando o horário com a colega e continuava as visitas domiciliares no período da manhã, na região da Volta do Brejo. A marcação dos pacientes era feita por ela mesma no momento da visita ou quando espontaneamente havia procura no próprio consultório. Vale ressaltar, que já num momento inicial houve o deslocamento da equipe de saúde bucal, separando-a fisicamente do restante do grupo.

Nos primeiros três meses do atendimento, março a julho de 2001, as atividades foram destinadas exclusivamente à população da Volta do Brejo. No entanto, conforme relato da profissional, após esse período ela passou a aten- 
der todas as urgências/emergências, independentemente da região do município de onde a pessoa viesse, seguindo uma determinação da Secretaria Municipal de Saúde. Isso gerou uma superlotação do consultório e impossibilidade de desenvolver as atividades propostas dentro dos princípios do programa.

Em agosto de 2001, a cirurgiã-dentista do PSF foi deslocada para o bairro Várzea das Flores, quando o município, recebendo incentivos do Governo Federal, montou um consultório odontológico na Unidade de Saúde lá existente. Esta seria a região já prevista para ser incorporada ao atendimento. O que ocorreu com essa mudança foi que a população da Volta do Brejo deixou de comparecer às consultas devido à distância desse bairro até a Várzea das Flores. As visitas também diminuíram e passou-se a atender quase que somente a população da Várzea das Flores.

Em novembro de 2001, a administração, atravessando dificuldades financeiras, dispensou todos os profissionais contratados, restando de um quadro de oito profissionais somente a "cirurgiã-dentista do PSF" - visto que para pagá-la utilizava-se do incentivo vindo do Ministério da Saúde. A partir daí, a dentista foi deslocada para o "posto de saúde" mais central e passou a atender urgências/emergências de todo o município; esse período teve aproximadamente 40 dias de duração.

Após esse período, a profissional retornou para o consultório da Volta do Brejo, porém com uma modificação na área de atuação. Desta vez, as áreas de abrangência seriam Volta do Brejo e Morro Doce, e não mais, Volta do Brejo e Várzea das Flores. O atendimento e as visitas eram feitos a essas duas regiões sendo assim até maio de 2002, quando a dentista pediu demissão do cargo.

As duas regiões ficaram desassistidas aproximadamente 30 dias, quando foi contratada uma nova profissional que desempenha as atividades da mesma forma desde então.

Não houve uma aproximação com os agentes comunitários para ajuda na atenção preventivo-promocional e a cirurgiã-dentista continua sozinha na realização de todas as atividades. Em função do término da fase de coleta de dados deste trabalho em agosto de 2002, não se têm mais informações sobre o andamento das atividades desde então.

\section{Objetivo}

O objetivo do trabalho foi avaliar alguns aspectos da inclusão da Saúde Bucal no PSF em uma área de um município de pequeno porte, Pompéu (MG), pelo olhar dos usuários.

\section{Metodologia}

O estudo foi realizado no bairro Volta do Brejo, região de abrangência da primeira equipe de PSF implantada no município de Pompéu. Essa escolha foi determinada levando-se em consideração a existência de dados epidemiológicos importantes sobre a região em questão, objeto de um estudo anterior (Andrade 8 ).

Para a coleta dos dados foi elaborado um questionário para os usuários do serviço. O trabalho foi aprovado pelo Comitê de Ética em Pesquisa da UFMG.

A definição do grupo de usuários foi determinada por cálculo amostral utilizando-se o método de estimativa de proporção e a variabilidade de 50\% em função do desconhecimento de dados em estudos anteriores. Para os cálculos considerou-se o grau de confiança de $90 \%$ e um erro admissível de 5\% (Levy e Lemeshow ${ }^{9}$ ).

Foram aplicados 120 questionários em 120 domicílios, respondidos pela pessoa adulta que se apresentava como a responsável pela casa, após ler e assinar o Termo de Consentimento Livre e Esclarecido e o Termo de Esclarecimento, ambos apresentados previamente pelo pesquisador. Todas as ruas e avenidas da Volta do Brejo foram visitadas. Procurou-se alternar os domicílios, visitando uma casa e passando-se pela seguinte sem incluí-la.

No questionário para os usuários, havia uma parte inicial constando de dados sociodemográficos como idade, sexo e renda familiar e outra objetivando colher informações sobre o nível de satisfação em relação aos serviços oferecidos pela equipe do Programa Saúde da Família, com questões envolvendo a equipe como um todo e outras questões somente relacionadas à odontologia. Conforme definição prévia no estudo piloto, o pesquisador lia o questionário integralmente para o participante, tomando-se o cuidado de não interferir durante a fala do mesmo. Todas as questões tinham de 6 a 7 opções de respostas e as observações feitas pelos usuários, consideradas relevantes, foram anotadas. Estas observações, não previstas anteriormente, constituíram-se na parte mais importante desta avaliação. 


\section{Resultados e discussão}

Dentre os 120 usuários estudados, na distribuição quanto ao sexo, observou-se que $76(63.3 \%)$ são mulheres e $44(36.6 \%)$ são homens. Segundo Ferreira Filho et al.6, este dado está de acordo com a maioria dos estudos realizados em serviços de saúde, nos quais a clientela feminina é sempre predominante. Além do mais, as entrevistas foram realizadas nos domicílios, onde as mulheres são mais facilmente encontradas.

Com relação à idade, os usuários foram agrupados em duas faixas etárias: de 20 a 40 anos (adultos jovens) e 40 ou mais anos (adultos). Assim sendo, 81 indivíduos $(67,5 \%)$ encontravam-se entre 20 e 40 anos e 39 indivíduos $(32,5 \%)$ com 40 anos ou mais.

Para a renda familiar, levou-se em consideração a renda total da família somando-se o ganho mensal de todos os moradores daquele domicílio. Das 120 famílias participantes, 91 $(75,83 \%)$ têm renda familiar total entre 1 a 2 salários mínimos e 29 (24,16\%) têm renda familiar total entre 2 a 3 salários mínimos.

São descritos a seguir, alguns dos principais pontos levantados na pesquisa, obtidos através da aplicação do questionário e da anotação das falas de alguns entrevistados.

No momento inicial da aplicação dos questionários, notou-se um direcionamento para as respostas positivas. Segundo Guedes \& Garcia 5 , as respostas dos usuários acerca de seu nível de satisfação quanto ao atendimento nos serviços dos SUS apresentam esta tendência positiva (ficando em torno de 40 a 50\%), devido ao receio do entrevistado que as respostas desfavoráveis possam resultar em algum tipo de sanção no atendimento. Por outro lado, o fato de o entrevistador não ser uma pessoa da comunidade contribui para a resposta negativa.

Quando questionados quanto à presteza no atendimento, responderam:

"Eu acho que demora assim mesmo. É assim em todo lugar de graça...".

"Eu não recebi tratamento até hoje e já pedi faz uns 9 meses. Mas tem gente que quando a dentista vem já marca na hora";

"Eu peguei a vaga do meu irmão porque ele estava preso";

"A gente põe o nome na fila e espera uns 2 anos. Meu vizinho quando eles chamaram já tinha até morrido".

As falas dos entrevistados mostram insatisfação quanto ao tempo de espera por um trata- mento. Não houve um planejamento de saúde no município, tomando-se como ponto de partida a realidade local, com relação aos problemas de saúde bucal, os recursos humanos, físicos e o apoio da comunidade. Sônia Groisman et al. 10 falam em seu estudo da importância de tal visão num processo de construção de um modelo de atenção em saúde segundo os princípios do Sistema Único de Saúde.

Quanto à resolutividade, a necessidade de mais vagas para o atendimento cirúrgico-restaurador e a falta do tratamento reabilitador no serviço foram as principais queixas. Quando as necessidades não são resolvidas no serviço local, não há um esquema de referência/contrareferência e os problemas ficam sem solução, já que não há como os usuários pagarem um tratamento no serviço privado.

"Tem coisa demais para nós. Meu filho trabalha na roça e vai com dor de dente todos os dias".

"Eu preciso de colocar uns dentes porque tá difícil demais para eu comer".

As ações de saúde bucal na estratégia da família devem expressar os princípios e as diretrizes do SUS e ter como objetivo ampliar o acesso da população às ações de saúde bucal, incluindo-as no conjunto de atividades desenvolvidas pelo PSF. Devido ao fato de o modelo de saúde de Pompéu estar repetindo o modelo tradicional, centrado na doença, e em função da grande demanda reprimida por anos de inexistência de qualquer tipo de atenção, os problemas da população não são resolvidos e as queixas são muito freqüentes.

Quando o usuário é questionado sobre as orientações passadas pelos agentes comunitários de saúde, a maioria dos entrevistados disse estar satisfeita com elas, mas pode-se perceber, por algumas falas, que não há um esclarecimento, nessa comunidade, do papel das agentes comunitárias de saúde e do PSF como um todo:

"O que é PSF? Aqui em Pompéu não tem isso não".

"Eu acho que essas visitas são para saber negócio de dengue".

"Vem, dá escova e só".

A construção de uma estratégia como a Saúde da Família deveria ocorrer juntamente com a comunidade que será assistida pelo programa, contemplando um dos princípios do SUS, que é a participação da comunidade. Não acontecendo desta forma, nota-se a dificuldade de o usuário reconhecer o PSF. Solla et al.11 mostraram que, além disso, há uma dificuldade de identificar com precisão sua lógica de funcio- 
namento. Os autores falam que à exceção das mulheres mais velhas, que vêem de um modo mais abrangente, a avaliação adquire uma característica fragmentada, calcada mais em experiências particulares e menos em uma visão geral de funcionamento do PSF. O programa, de fato, é muito mais identificado a partir de sua materialização em um Posto de Saúde e nas ações de seus profissionais.

Quando questionados sobre a forma como são abordados os assuntos, parece que os profissionais estão despreparados para passar as informações, muitas vezes fazendo-o de forma autoritária o que demonstra que há falta de um treinamento de toda a equipe para abordar determinados assuntos:

"Olha eu não estou satisfeita não. O povo vem e fala que não pode fazer coisas de açúcar porque estraga os dentes. Mas eu faço porque mesmo se nós não comermos o dente estraga do mesmo jeito".

"Às vezes eles xingam a gente porque a gente come doce e não escova os dentes direito, mas é preciso entender que nós não sabemos, não é?"

"Só que eles mandam a gente parar de fazer um monte de coisa e ainda tem que escovar".

O despreparo da equipe e a falta de um treinamento e capacitação ficaram evidentes. $\mathrm{O}$ processo de contratação é feito sem concurso público e o favorecimento político para a ocupação dos cargos é marcante.

Araújo et al.12 avaliaram o conhecimento dos agentes comunitários sobre saúde bucal em Belém do Pará e mostraram em seu estudo que o preparo destes profissionais não é suficiente para se alcançarem os objetivos propostos na filosofia de promoção de saúde e no âmbito do Sistema Único de Saúde.

Para que os profissionais possam responder satisfatoriamente à complexidade dos problemas de saúde, além de estarem engajados no processo de reorganização dos serviços é necessário criar condições para os processos de formação e capacitação destas pessoas (Corneta et al.13). No entanto, no município de Pompéu, não se pode notar tais condições.

Algumas pessoas relataram o fato de a necessidade da atenção curativa ser maior e por isso, apesar de considerarem boas as visitas, os seus problemas ficam sem solução.

"Só que eu preciso mais é de arrumar meus dentes".

"Mas só conversa não sara a dor de dente".

"As visitas são muito boas, a gente aprende como faz para escovar, mas também fica só nisso".
As respostas negativas eram explicadas pelo fato de que a necessidade de tratamento não era solucionada com as visitas domiciliares.

"Não fui atendido ainda. A dentista só veio e deu escova".

"É em parte porque já recebi visita, sei como que escova, sei que não pode comer doce, mas eu preciso é de tratar. Meus dentes estão ruim demais".

"Eu queria demais colocar uma chapa, gente!"

"Eu acho que é bom aprender. Mas eu quero é tratar dos dentes, porque escovar eu já sei”.

Este aspecto foi discutido por Guedes e Garcia $^{5}$, ao mostrarem em seu estudo que quando as pessoas se mostram insatisfeitas com o tratamento recebido, este está relacionado com o tratamento preventivo. Como a necessidade curativa supera a atenção preventivo-promocional, os indivíduos atendidos em situações de urgência/emergência, em geral, mostram-se satisfeitos, da mesma forma que aqueles que fazem um tratamento seqüencial.

Neste mesmo contexto, reclamaram da constante troca de profissionais, o que os impede de criarem vínculos com o serviço.

"Só que troca muito de médico".

"Mudou de dentista lá. A outra que entrou eu não sei".

Quando afirmavam gostarem muito das visitas, ficou claro que as conversas serviam também como desabafo para aquelas pessoas. Solla et al.11 enfatizaram que a escuta e a gentileza dos profissionais são fundamentais para uma avaliação positiva.

"Essas conversas são boas porque a gente põe pra fora o que sente".

Quando questionados sobre quem procurar para solucionar problemas relacionados com a boca, um número satisfatório de pessoas relatou ir até os agentes comunitários. Isto pode ser explicado pela proximidade entre estes profissionais e os usuários, porque são pessoas da própria comunidade e que vivem os mesmos problemas. Em seu estudo, Solla et al.11 avaliaram o grau de satisfação dos usuários com o trabalho dos agentes comunitários de saúde no estado da Bahia. Os resultados apresentados foram considerados positivos na medida em que mais de 70\% das pessoas responderam afirmativamente sobre o bom desempenho dos agentes comunitários de saúde. Isso ratifica a importância desses profissionais e de sua atuação com a população.

Os Agentes Comunitários de Saúde (ACS) são identificados pelos usuários como alguém 
que desempenha o papel de mediador entre a comunidade e os profissionais de saúde. Ou seja, são valorizados pelo fácil trânsito que dispõem no sistema formal de atenção à saúde, $o$ que torna menos árduo o processo de acesso ao cuidado (Trad et al. $\left.{ }^{1}, 1998\right)$.

"Eu ia falar com as meninas".

"As meninas, as agentes, de vez em quando arrumam um jeito da gente arrancar um dente".

"Eu acho que tem que falar é com o dentista que é médico de cuidar de dente. Mas, como é que faz? Nunca que eles vão receber a gente, quase não tem vaga, não é mesmo?!”

O enfermeiro também é uma figura muito importante para a comunidade pois coordena a maioria das atividades do PSF e aparece mais para o público como participante ativo no processo de educação em saúde. Para Morita et $a l .14$, os profissionais de enfermagem são prestadores diretos de atenção à saúde e viabilizam a relação entre o serviço e a clientela.

Quanto à facilidade de acesso ao consultório odontológico (situado dentro da Escola Municipal do bairro) ou à Unidade de Referência da Saúde da Família, uma vez que ambos são bem próximos, 109 (90,8\%) entrevistados responderam que era muito fácil o acesso. Ambos são localizados na região mais central do bairro, próximos um do outro e de fácil acesso para todos os moradores. Somente $10(8,4 \%)$ responderam negativamente, $1(0,8 \%)$ não respondeu. Nesta questão pode-se verificar que para a comunidade a existência de uma unidade de saúde próxima aos seus domicílios é muito importante não só pelo fato da facilidade de acesso até lá, como também por facilitar a vida de pessoas que têm filhos e que precisam deixá-los sozinhos quando têm de ir ao serviço de saúde. Este aspecto foi estudado por Regis Filho \& Lopes 7 (1996) e vem sendo confirmado neste estudo.

Deve-se levar em consideração que apenas uma área foi pesquisada. A outra região assistida também por esta equipe odontológica não foi questionada. Se isto tivesse ocorrido, com certeza a avaliação não seria tão positiva devido à distância entre os dois bairros.

"Tem dia que a gente chega passando mal e em plena segunda-feira não tem médico para atender. Isso é um absurdo!"

"Porque o médico passou a receita e nem olhou para a minha cara".

"Não pára médico no posto e também eles não gostam muito de atender a gente não".

$\mathrm{Na}$ maioria das vezes, o fato de nem sempre se encontrar o profissional quando necessário foi muito enfatizado. A constante troca de profissionais impedindo a criação de vínculos com a população assistida foi outro ponto criticado pelos participantes da pesquisa.

Alguns entrevistados afirmavam que o fato de algumas pessoas receberem as visitas e outras não mostrava que o serviço era desorganizado.

"O que eu acho pior é que os agentes nunca vieram aqui".

Com relação à odontologia os participantes relataram que a dificuldade em conseguirem o tratamento era bem maior quando comparado ao atendimento médico.

"Médico se a gente tiver paciência a gente até consegue, mas dentista nem com muita espera".

"Dentista é o pior. A gente não consegue vaga de jeito nenhum".

"O pior de tudo é dentista. A gente precisa e não tem”.

\section{Conclusões}

O trabalho da equipe do PSF na região estudada existe de forma tão precária que não pode ser percebido pelos usuários.

A população relata o pouco comprometimento dos profissionais com o serviço o que impede a criação de vínculos com a comunidade, que vê no favorecimento político, no fator sorte e na proximidade com os ACS uma alternativa para resolver ou minimizar os seus principais problemas de saúde.

As soluções para tais problemas parecem sufocadas por uma grande demanda reprimida e pelo andamento inadequado das atividades no PSF, que vem sendo mantido no município devido aos incentivos financeiros.

A inserção da odontologia parece ter sido de direito, mas não de fato. Os "problemas de boca" continuam sendo de responsabilidade da odontologia, que não consegue solucioná-los em função da grande demanda acumulada.

Os princípios do PSF são perdidos pela grande demanda reprimida e dificuldades administrativas, distanciando o serviço da proposta de melhoria da qualidade de vida da população.

Os usuários do PSF do bairro Volta do Brejo encontram-se insatisfeitos com a presteza no atendimento, reclamando das longas filas de espera e não conseguindo resolver a maioria dos seus problemas de caráter emergencial. Quando respondem positivamente à questão, o fazem com aceitação e resignação. 
Com relação à resolutividade, a grande maioria reclama da falta ou inadequada atenção curativa recebida. Porém, mostram que a presença dos ACS é importante para conseguirem o atendimento e que a proximidade com a unidade de saúde de referência é muito importante para eles.

O trabalho da equipe de PSF não é percebido pelos usuários, que desconhecem o Programa Saúde da Família e a inclusão da odontologia neste Programa e vêem no atendimento médico e no atendimento odontológico o que há de pior no que eles percebem como PSF.

Sônia G et al. 10 mostram em seu estudo sobre a evolução da saúde bucal no Brasil que os problemas de ordem estrutural acontecem em unidades básicas de saúde comuns e também em locais onde a saúde bucal vem sendo inseri-

\section{Colaboradores}

KLC Andrade e EF Ferreira participaram igualmente de todas as etapas da elaboração do artigo.

\section{Referências}

1. Trad LAB, Bastos ACS. O impacto sociocultural do Programa de Saúde da Família (PSF): uma proposta de avaliação. Cad Saúde Pública 1998; 14(2):429-35.

2. Brasil. Ministério da Saúde. Projetos e Programas. Saúde da Família. Disponível em www.saude.gov.br. 2000.

3. Santos MP. Avaliação da qualidade dos serviços públicos de atenção à saúde da criança sob a ótica do usuário. Rev Bra Enferm 1995; 48(2):109-19.

4. Vasconcelos EM. A priorização das famílias nas políticas de saúde. Rev Saúde em Debate 1999; 23(53):6-19.

5. Guedes DGM, Garcia TR. Atendimento nos serviços do Sistema Único de Saúde e satisfação do usuário: estudo no município de Campina Grande (PB). Rev Saúde em Debate 2001; 25(59):40-9.

6. Ferreira Filho JS, Cavalcanti MT, Cadilhe GR, Vilaça AT, Avancini E, Machado HO et al. Avaliação de qualidade de serviços de saúde mental no Município de Niterói - RJ. A satisfação do usuário como critério avaliador. J Bras Psiquiat 1996; 45(7):393-402.

7. Regis Filho GI \& Lopes MC. Estudo de clima organizacional em serviços ambulatoriais de saúde pública. Primeira parte: Perfil dos usuários e nível de satisfação. Itajaí: Secretaria Municipal de Saúde; 1996.

8. Andrade KLC. Prevalência de cárie dentária no município de Pompéu-MG (monografia). Belo Horizonte: Unaerp; 2000.

9. Levy PS, Lemeshow S. Sampling of populations: meth- da no PSF. Estes fatos são reflexo da insuficiência de pessoal e de recursos financeiros e também do despreparo de gestores na construção dos modelos de atenção.

Os resultados da pesquisa foram apresentados à equipe, a fim de contribuir para a reorientação dos profissionais e para uma possível discussão juntamente com os gestores sobre as mudanças que geraram a descontinuidade aos serviços. Além disso, houve um esclarecimento sobre a importância da participação popular no SUS, enfatizando-se o PSF como um promotor desta participação e também da importância dos conselhos municipais para discussão, com a comunidade, dos pontos positivos, pontos negativos e alternativas para melhorar o sistema de saúde local. ods and applications. New York: John Wiley and Sons; 1991.

10. Groisman S, Moraes NM, Chagas LD. A evolução da atenção à saúde no Brasil: o contexto da saúde bucal. Rio de Janeiro: Cadernos da ABOPREV II; 2005.

11. Solla JJSP, Medina MG, Dantas MBP. O PACS na Bahia: avaliação do trabalho dos agentes comunitários de saúde. Rev Saúde em Debate 1996; 51: 4-15.

12. Araújo IC, Costa MA, Moraes NM. Avaliação dos conhecimentos sobre saúde bucal dos agentes comunitários de saúde no Programa Família Saudável de Belém do Pará. In: Anais VII Jornada de Saúde Bucal da Amazônia. Belém; 2003. p. 71.

13. Corneta VK, Maia CCA,Costa WGA. A reorganização dos serviços de saúde no sistema único de saúde e a formação de recursos humanos. Rev Saúde em Debate 1996, 51:44-9.

14. Morita I, Maeda ST,Costa ES, Araújo AS. Reflexões sobre a coerência discurso-prática no processo de interação usuário e equipe de enfermagem: uma experiência no Centro de Saúde Escola de Botucatu. Rev Saúde em Debate 2001; 25(59):50-8.

Artigo apresentado em 18/07/2005

Aprovado em 18/10/2005

Versão final apresentada em 18/10/2005 